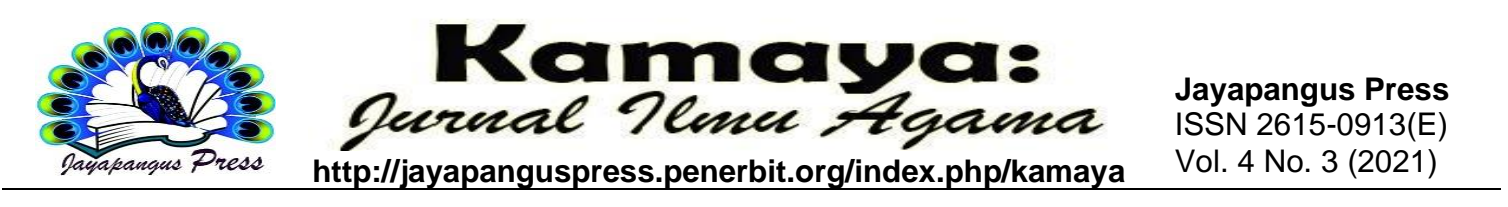

\title{
Kagedong : Ekspresi Interaksi Teruna Nyoman Dan Daha Di Desa Adat Tenganan Pegringsingan
}

\author{
Ni Ketut Kantriani ${ }^{1}$, Ni Wayan Arini' ${ }^{2}$, Gusti Nyoman Mastini ${ }^{3}$ \\ ${ }^{123}$ Universitas Hindu Negeri I Gusti Bagus Sugriwa Denpasar \\ ${ }^{1}$ ketutkantriani@gmail.com, ${ }^{2}$ wayanarini1967@gmail.com, \\ ㅍnyomanmastini2@gmail.com
}

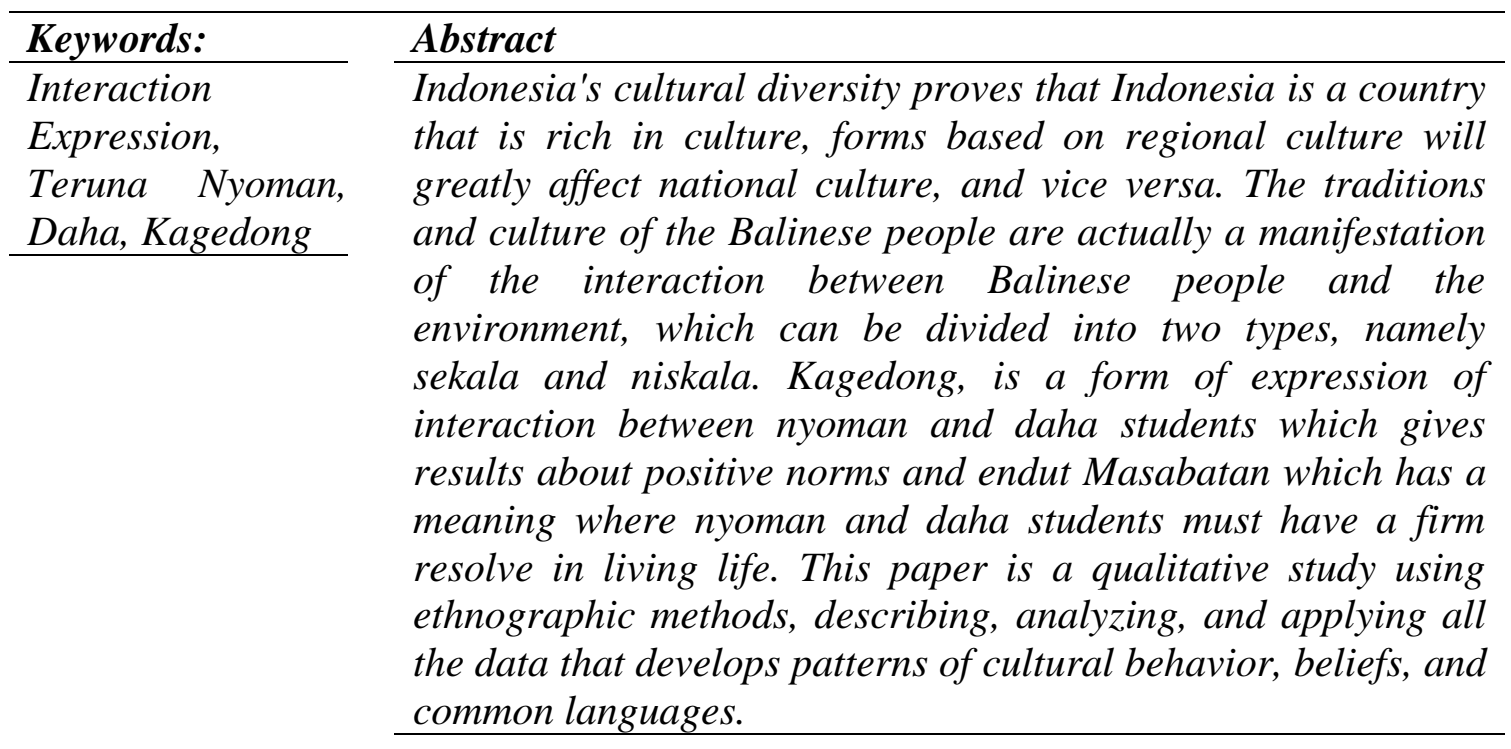

Kata Kunci:

Ekspresi Interaksi, Teruna Nyoman, Daha, Kagedong

\begin{abstract}
Abstrak
Keanekaragaman budaya Indonesia membuktikan bahwa Indonesia adalah negara yang kaya akan budaya, bentuk yang berbasis budaya daerah akan sangat mempengaruhi budaya nasional, begitu pula sebaliknya. Tradisi dan budaya masyarakat Bali sebenarnya merupakan manifestasi dari interaksi antara masyarakat Bali dengan lingkungan, yang dapat dibedakan menjadi dua jenis, yaitu sekala dan niskala. Kagedong, merupakan bentuk dari ekspresi interaksi antara teruna nyoman dengan daha yang memberikan hasil tentang norma-norma positif serta Masabatan endut yang memiliki makna dimana teruna nyoman serta daha harus memiliki ketetapan hati yang teguh dalam menjalani kehidupan. Karya tulis ini merupakan studi kualitatif dengan menggunakan metode etnografi, mendeskripsikan, menganalisis, dan menafsirkan semua data dari seperangkat bidang yang mengembangkan pola perilaku budaya, kepercayaan, dan bahasa umum.
\end{abstract}




\section{Pendahuluan}

Kebudayaan merupakan aset yang sangat berharga, karena tidak hanya menjadi ciri khas suatu daerah, tetapi juga merupakan lambang individualitas suatu bangsa atau daerah. Karena budaya adalah kekayaan dan ciri khas suatu daerah, maka menjadi tanggung jawab setiap orang untuk membudidayakan, menjaga dan melestarikan budaya. Definisi budaya yang sering disebutkan dalam kajian budaya Indonesia adalah yang dikemukakan oleh antropolog Indonesia Koentjaraningrat dan Parsudi Suparlan. Menurut Koentjaraningrat (1997), budaya diartikan sebagai suatu nilai yang diperoleh melalui proses belajar, tingkah laku, dan keseluruhan sistem kerja manusia dalam kehidupan manusia. Budaya merupakan suatu pedoman untuk menjalin hubungan komunikasi antar manusia dengan lingkungannya. (Parsudi Suparlan, 1986)

Indonesia adalah negara di mana orang-orang dengan bahasa, budaya, dan tradisi yang berbeda hidup bersama. Keanekaragaman budaya Indonesia membuktikan bahwa Indonesia adalah negara yang memiliki kekayaan budaya. Tak dapat dipungkiri bahwa budaya lokal adalah unsur utama dalam membangun budaya yang lebih mengglobal, yaitu budaya nasional (Brata, 2016). Oleh karena itu, berbagai bentuk budaya daerah akan berdampak kuat terhadap budaya nasional, dan sebaliknya budaya nasional yang timbul dari budaya daerah juga akan berdampak kuat terhadap budaya daerah.

Membahas tentang kebudayaan, masyarakat Bali memiliki tradisi yang beraneka ragam. Pada setiap daerah di Bali memiliki kekhasan tradisi yang berbeda-beda dalam pelaksanaan upacara keagamaan.' 'setiap tempat memiliki tata cara upacara yang dilaksanakan sesuai dengan loka dresta (desa kala patra dan desa mawacara) setempat" (Karda, 2007:43 dalam manuaba, 2011:1). Banyaknya tradisi yang terdapat di Bali membuat Bali menjadi pusat perhatian dari para pendamba tradisi dan budaya, salah satu tradisi yang unik dan mengandung nilai-nilai moral yang tinggi, yakni tradisi kagedong yang terdapat di desa Bali Aga, desa adat Tenganan Pegringsingan, Karangasem Bali. Masyarakat Bali Aga yang tepatnya di Desa adat Tenganan Pegringsingan ini, memiliki corak dan karakter yang unik dibandingkan dengan masyarakat Bali pada umumnya. Yang berbeda adalah adat dan tradisi yang baik tetap dipertahankan, yang berpegangan teguh pada aturan adat (awig-awig). Tradisi Kagedong merupakan salah satu rangkaian dari tradisi besar dalam indikasi pendidikan informal bagi masyarakat desa adat Tenganan Pegringsingan yakni Materuna Nyoman, yang merupakan proses metamorphosis calon teruna menjadi teruna yang sah secara 
adat (sekala dan niskala). Tradisi Kagedong masih berpegang teguh sama seperti apa yang telah diwariskan oleh para leleuhur desa adat Tenganan Pegringsingan, meskipun seiring dengan kemajuan jaman, tradisi dan budaya yang sejak awal dilestarikan, dijunjung, dan dijunjung tinggi oleh setiap masyarakat di daerahnya masing-masing, kini sudah hampir bergeser dalam konteks pelaksanaan, tujuan dan nilai yang terkandung di dalamnya, bahkan dapat dikatakan berada di ambang kepunahan.

Jika melihat kondisi seperti saat ini, orang masih merasa gengsi dan malu ketika masih memperkenalkan budaya daerahnya. Pada umumnya, orang memilih untuk mempelajari dan memperkenalkan budaya modern, bukan budaya dari daerah yang sebenarnya budaya daerah yang sesuai dengan karakter bangsa. Orang-orang yang kurang memiliki kepedulian terhadap budaya daerahnya, lebih memilih untuk bermigrasi ke budaya asing yang bahkan belum tentu sesuai dengan kepribadian negara, selain itu kebanggaan masyarakat terhadap budaya luar melebihi budaya dari daerahnya sendiri. Budaya lokal merupakan kekayaan suatu bangsa dan memiliki nilai yang luhur. Hal itu harus dilestarikan dan dilestarikan oleh semua orang di masyarakat. Secara umum, mereka tidak menyadari bahwa budaya sebenarnya merupakan ciri khas bangsa yang mencerminkan segala aspek kehidupan yang dikandungnya.

Berdasarkan keresahan saat ini terhadap nilai-nilai budaya maupun tradisi yang semakin memudar, namun terdapat sinar harapan oleh mayarakat Bali Aga, maka besar harapan peneliti untuk menggali proses tradisi Kagedong yang masih terjaga baik secara pelaksanaan dan tujuannya yang terdapat di desa adat Tenganan Pegringsingan sebagai bentuk pemertahanan ekspresi interaksi budaya.

\section{Metode}

Metode yang digunakan pada karya tulis ilmiah ini adalah penelitian kualitatif melalui metode etnografi dengan cara mencatat setiap data yang diperoleh dari lapangan. Desain penelitian etnografi juga merupakan metode penelitian kualitatif, yang menggambarkan, menganalisis, dan menjelaskan sekelompok budaya yang berkembang dari waktu ke waktu-pola perilaku, kepercayaan, dan bahasa umum yaitu Tradisi Kagedong masyarakat Desa Adat Tenganan Pegringsingan. 


\section{Hasil dan Pembahasan}

Masyarakat adat telah mengembangkan sistem pengelolaan lokal mereka di masa lalu. Sistem manajemen tingkat daerah atau sistem manajemen adat umumnya didasarkan pada peraturan adat, berdasarkan praktik umum, adat istiadat, kepercayaan, dan pengetahuan kearifan lokal dengan kondisi khusus. Keberadaan nilainilai tersebut adalah modal bagi masyarakat, yang dapat dijadikan sebagai dasar atau alat untuk mengendalikan laju kerusakan lingkungan akibat kegiatan pembangunan yang membawa serangkaian perubahan dan permasalahan. Hal ini juga berlaku dalam kehidupan masyarakat desa adat Tenganan Pegringsingan yang memiliki kearifan lokal atau ciri khas tersendiri sebagai tata nilai tradisional yang tertuang dalam awigawig (hukum adat).

Tenganan Pegringsingan merupakan sebuah desa tua atau biasa disebut desa Bali Aga yang terletak di Kecamatan Manggis, Kabupaten Karangasem. Desa adat Tenganan Pegringsingan merupakan desa yang masih menjunjung tinggi pola hidup dengan tata masyarakatnya yang mengacu pada aturan adat desa yang diwariskan oleh para leluhur atau pendahulunya. Kata Tenganan berasal dari kata "tengah" atau "ngatengahang" yang memiliki arti "bergerak ke daerah yang lebih dalam". Istilah tersebut mengacu pada pergeseran masyarakat pedesaan dari daerah pesisir ke pemukiman di tengah perbukitan

Prasasti yang dapat mengungkapkan asal usul sejarah desa tidak ada lagi karena desa tradisional Tenganan Pegringsingan mengalami kebakaran pada tahun 1841 (Masehi) atau 1763 (Isaka), dan pada tahun 1841 semua dokumen desa hangus, namun untuk mengetahui asal usul desa adat Tenganan Pegringsingan dapat dikemukakan dalam beberapa cerita mitologi yang sampai kini samar-samar masih hidup di kalangan masyarakat Tenganan khususnya, Maupun masyarakat Bali umumnya. Sejarah mengenai asal usul Desa Adat Tenganan Pegringsingan ini masih dapat dilihat di dalam Usana Bali yang berisi tentang asal usul Bali yang ditulis oleh Ida Pedanda Sakti Wawu Rauh .

Tradisi dan budaya Bali sebenarnya merupakan manifestasi dari interaksi antara masyarakat Bali dengan lingkungan. Dalam mempelajari asal-usul Bali, lingkungan dibagi menjadi dua jenis, yaitu sekala (nyata) dan niskala (tidak nyata). Manifestasi interaksi antara masyarakat Bali dengan lingkungan spiritual (niskala) menyebabkan terciptanya sistem keagamaan lokal, yang dalam perkembangannya kemudian 
mencampurkan keberadaan agama lokal dengan aspek-aspek Hindu yang tercipta dari proses pertemuan budaya masa lalu. Masyarakat Bali berinteraksi dengan lingkungan sosial di Bali (Bali), Norma-norma, aturan, hukum (sima, dresta, awigawig), aturan kekerabatan (nyama, braya, dadia, soroh) dan aturan sosial (sekeha, banjar, desa, gumi) dan sebagainya. Ekspresi interaktif masyarakat Bali dan lingkungan alam telah melahirkan sistem pengetahuan alam (seperti kalender bulanan, Pawukon, Pramatamangsa), sistem Subak, dll. (Puja astawa, 2001)

Kagedong, merupakan bentuk dari ekspresi interaksi antara teruna nyoman dengan daha yang sesungguhnya kagedong masuk dalam rangkaian prosesi materuna nyoman sebagai bentuk metamorphosis teruna nyoman menjadi teruna seutuhnya, dalam tradisi kagedong dapat dikatagorikan sebagai layaknya proses kepompong, yang terbungkus dengan kuat dan tidak terlihat wujud didalam kepompong tersebut, hal ini sama dengan tradisi kagedong yang tidak boleh terlihat oleh siapa pun termasuk kedua orang tuanya, namun sebelum Padewasaan atau Kagedong dilaksanakan, para teruna nyoman terlebih duhulu wajib di potong rambutnya hingga habis (digundul) hal ini bertujuan agar para teruna nyoman merasakan kebersamaan atau penyamarataaan yang sama diantara peserta lainnya, tidak ada yang dibedakan melalui golongan ataupun status keluarga, semua terlihat sama. Hal ini merupakan bentuk dari ekspresi interaksi nyata yang menandakan bahwa setiap manusia sesungguhnya adalah sama. Setelah para teruna nyoman dipotong rambutnya, selanjutnya melakukan upacara Matatah (dibaca; prosesi potong gigi menurut kepercayaan Hindu di Bali), upacara matatah ini memilki makna yang sama dengan upacara matatah yang terdapat di Bali pada umumnya, yakni menekan unsur-unsur dari Sad Ripu yang dikenal dengan enam musuh yang ada dalam diri manusia, diantaranya : 1). Kama yakni hawa nafsu, 2). Lobha yakni sifat tamak/rakus, 3). Krodha yakni sifat marah, 4). Moha yakni kebingungan, 5). Mada yakni sifat mabuk (kemabukan), 6). Matsarya yakni sifat iri hati. Namun secara pelaksanaan upacara serta upakaranya sangat berbeda dengan di Bali pada umunya, prosesi matatah di Desa Adat Tenganan Pegringsingan cendrung bersifat sederhana namun penuh makna, dengan pelaksanaanya berdasarkan simbolis melalui ketukan pada gigi seri dan gigi taring sebanyak tiga kali.

Setelah semua teruna nyoman selesai potong rambut dan matatah, maka para teruna Nyoman selanjutnya membersihkan diri secara jasmani dan rohani, pembersihan ini dilakukan sebelum memulai upacara kagedong, dan proses pembersihan diri ini 
disebut dengan Masigsig Ambuh, yakni proses pembersihan yang menggunakan sarana Baas Matunu (beras yang dibakar), Kikihan Kunyit (kunyit parut) yang digunakan sebagai Boreh (lulur), dan Lengis Miik (minyak wangi). Setelah selesai melaksanakan pembersihan diri, langkah awal dalam prosesi Kagedong adalah melakukan upacara persembahyangan di asrama, tepatnya di Sanggah Pamurukan/Guru bersama Jro Mekel yang bertujuan untuk memohon restu serta keselamatan dalam melakukan upacara kagedong, setelah selesai melakukan persembahyangan bersama maka teruna nyoman siap untuk upacara kagedong.

Menurut Yudiana (wawancara 17 Juni 2020) menyatakan bahwa kagedong berasal dari kata Gedong atau rumah yang dibangun dengan mengunakan bedeg (sejenis anyaman dari bambu) bedeg ini dibuat oleh para Teruna bani dan Teruna Pengawin yang merupakan senior dari peserta Teruna Nyoman lalu bedeg ini disusun berbentuk segi empat tanpa atap dan lantai yang dilengkapi dengan Sanan (bambu yang difungsikan sebagai alat bantu pikul). Setelah Gedong ini siap barulah Teruna Nyoman masuk kedalamnya, tujuannya masuk ke dalam gedong yakni agar tidak terlihat oleh siapapun termasuk oleh kedua orangtua mereka, yang boleh melihat peserta Teruna Nyoman hanyalah teruna-teruna yang terlibat dalam upacara Kagedong tersebut.

Para Teruna Nyoman mulai masuk ke dalam Gedong, lalu diberikan Base Buel (daun sirih yang dilinting) untuk dimasukan kedalam mulut, namun tidak boleh dimakan atau pun dikunyah, hanya digigit dan tidak boleh jatuh, hal tersebut memilki maksud agar para teruna Nyoman tidak berbicara dan menahan segala perkataannya, hal ini menggajarkan ekspresi interaksi yang memberikan hasil tentang norma-norma positif dalam kehidupan bahwasannya para teruna nyoman, agar dikala berbicara hendaklah berpikir dahulu dan ucapkanlah perkataan yang pantas dan baik.

Setelah masuk ke dalam Gedong, maka Gedong ini diangkat/dipikul hanya oleh Teruna Pengawin (senior satu tingkat lebih tinggi dari Teruna Nyoman) sedangkan Teruna Bani (Penegenan Base) membawa sarana perlengkapan upacara berupa Base (sirih), Buah (biji pinang), Uyah (garam) serta aneka macam buah dan jajan yang dijadikan satu lalu dipikul menggunakan batang tebu. Kagedong ini dimulai dari asrama atau rumah Jro Mekel lalu berjalan menuju Subak/Gantih Daha, mulai dari Gantih Wayah, Gantih Nengah lalu Gantih Nyoman. Proses dari Kagedong ini diibaratkan dengan kepompong yang tidak boleh terlihat atau sering disebut dengan fase kapingit (rahasia). Senada dengan hasil data di atas, menurut Ketut Sudiastika (wawancara 17 
Juni 2020) juga menyatakan kagedong merupakan proses yang bersifat rahasia, Kagedong dilaksanakan tiga kali selama tiga hari sekali yakni setiap Beteng, mulai dari Asrama menuju Gantih Daha dan dalam prosesnya para peserta Teruna Nyoman di ajarkan untuk menahan segala macam godaan dan tidak boleh berkata apapun di dalam kondisi apapun karena meraka hendaknya melihat terlebih dahulu lalu pelajari dengan baik.

Berdasarkan hasil wawancara tersebut Kagedong merupakan upacara yang sangat disucikan, Kapingit (rahasia) yang prosesnya diawali dari asrama menuju Gantih Daha yang dilaksanakan selama tiga kali selama tiga hari sekali yakni setiap beteng, dalam prosesnya para peserta Teruna Nyoman harus taat dalam pelaksanaannya dengan menahan segala bentuk godaan yang terjadi dalam prosesnya, sebuah hasil ekspresi interaksi yang berlangsung dalam proses Kagedong dengan hasil etika dalam berprilaku.

Setibanya di gantih daha wayah, peserta teruna nyoman duduk di Bale Buga bagian utara dan daha wayah duduk di bagian selatan, meskipun berada dalam posisi berdampingan, teruna nyoman dan daha tidak boleh terlihat satu sama lainnya, mereka diberikan bidang pembatas (sekat) pada bagian tengah Bale Buga. Penegenan Base lalu memberikan seserahan kepada Keliang Daha Wayah, lalu dilanjutkan dengan sebuah ritual yang sarat akan makna yaitu upacara Masabatan Endut, oleh Teruna Pengawin terhadap Daha. Masabatan Endut merupakan rangkaian upacara Kagedong yang memilki makna keteguhan hati teruna nyoman yang mengetahui meskipun hanya dengan mendengar Daha yang dilempari endut oleh teruna pengawin. endut (lumpur) ini terbuat dari campuran Endut (lumpur) dengan kotoran kerbau (Jro Gede Ombo) yang ada di Desa Adat Tenganan Pegringsingan dicampur menjadi satu oleh Teruna Pengawin, karena Teruna Pengawin saja yang diperbolehkan membuat Endut tersebut, namun hanya Teruna Pengawin yang memiliki hubungan kekeluargaan dengan para Daha Gantih Wayah.

Kagedong dan masabatan endut dilakukan pada masing-masing gantih daha, pertama gantih wayah, setelah selesai di gantih wayah, lalu para peserta teruna nyoman melanjutkan perjalanan menuju gantih nengah, yang sesampainya disana juga melakukan prosesi yang sama seperti halnya di gantih wayah, namun dalam masabatan endut, daha yang dilempar endut berbeda-beda sesuai dengan gantih tempat daha berasal, setelah prosesi di gantih nengah selesai lalu dilanjutkan terkhir di gantih nyoman dengan prosesi yang sama. upacara kagedong ini terus berlangsung sampai tiga 
kali dimasing-masing gantih daha selama tiga hari sekali yakni saat penanggalan tri wara beteng (sesuai dengan sistem penanggalan kalender desa adat tenganan pegringsingan).

Masabatan endut, di mulai dengan masamodana (mengucapkan mantra) oleh teruna bani untuk meminta izin kepada sesuhunan sekaligus sebagai pertanda akan dimulainya masabatan endut, disaat teruna bani mengucapkan samodana, disaat yang bersamaan olahan endut tersebut juga dilempar oleh para teruna pengawin yang tidak memiliki hubungan keluarga dengan daha gantih wayah, disaat para teruna pengawin melempar endut kepada daha gantih wayah, daha (gadis) tidak diperkenankan menghindar, emosi ataupun berbicara kasar (mengumpat) dan para daha hanya boleh menutup dirinya dengan kain hingga kepala tanpa menutupi wajahnya, namun terdapat aturan dalam pelemparan endut dan tidak boleh melempar secara sembarang, pelemparannya dengan tangan seperti meminta (posisi telapak tangan diatas) lalu lemparkan endut tersebut. Melempar endut ini dilakukan berkali-kali hingga Teruna Bani selesai mengucapakan Samodana (mantra). Masabatan endut bermakna bahwa teruna nyoman serta daha harus memilki keteguhan hati dalam menjalani kehidupan di masa yang akan datang, apapun bentuk ujian dan tantangan yang dihadapi, tidak bertindak ceroboh dan emosi yang dapat menumbuhkan/menguatkan kepribadian moral, dimana keteguhan hati para teruna nyoman dan daha diuji dalam masabatan endut, semua makna yang terkandung dalam prosesi ini kelak akan menjadi bekal bagi para teruna nyoman dan daha dikehidupan berkeluarga nanti. Hal tersebut tak terlepas dari ekspresi interaksi antara para teruna nyoman, teruna pengawin, teruna bani dan para daha secara niskala melahirkan sistem keagamaan lokal, yang meliputi emosi ataupun perasaan keagamaan, dan konsep kekuatan batin yang kuat.

\section{Kesimpulan}

Tiga konsep penting yang berkaitan dengan tradisi dan budaya meliputi: a). sistem nilai, b). tindakan, dan c). kerja. Sistem nilai, perilaku dan karya sebenarnya adalah tiga manifestasi dari tradisi dan budaya. Kebudayaan berupa sistem nilai (kebudayaan berupa pemikiran) meliputi nilai, norma, aturan, hukum, dan adat istiadat. Esensinya amatlah abstrak (tidak terlihat atau dapat diakses) dan tersimpan dalam benak setiap anggota masyarakat. Meskipun abstrak, ia ada dan berfungsi sebagai pedoman untuk mengatur perilaku atau perilaku manusia. Semua perilaku manusia yang dipandu 
oleh nilai, norma, aturan, hukum, dan adat istiadat disebut "tindakan berpola" atau action. Sebagai makhluk berbudaya, sebagian besar perilaku manusia tergolong perilaku terpola, dan hanya sebagian kecil saja yang tidak tergolong perilaku atau perilaku berpola. Kagedong merupakan proses yang berpola dengan terciptanya ekspresi interaksi yang lebih menekankan nilai-nilai etika, moral dan lainnya yang memacu karakter teruna nyoman maupun daha menjadi pribadi yang lebih baik dan tentunya bertanggung jawab yang muncul sebagai rasa masing-masing teruna nyoman maupun daha.

\section{Daftar Pustaka}

Awig-Awig. (1841). Bali;karangasem; Desa Adat Tenganan Pegringsingan Patent Bagus, I. G. (2002). Kebudayaan Bali. Jakarta: Djambatan.

Brata, I. B. (2016). Kearifan budaya lokal perekat identitas bangsa. Bakti Saraswati, 15.

Koentjaraningrat. ( 2002). Manusia dan Kebudayaan di Indonesia. Jakarta: Djambatan.

Koentjaraningrat. (1997). Pengantar Antropologi, Pokok-Pokok Etnografi II. Jakarta: Rineka Cipta.

Koentjaraningrat. ( 1992). Beberapa Pokok Antropologi Sosial. Jakarta: Dian Rakyat.

Miharja, D. (2013). Adat, Budaya dan Agama Lokal Studi Gerakan Ajeg Bali Agama Hindu Bali. Bali: Kalam.

Moleong, L. (2013). Metedologi Penelitian Kualitatif Edisi Revisi. Bandung: Remaja Rosdakarya.

Ngurah, I Gusti Made, dkk. . (2006). Buku Penelitian Agama Hindu Untuk Perguruan Tinggi. Surabaya : Paramita.

Noronha, R. (1976). Paradise Reviewed: Tourism in Bali. New York: Oxford University Press.

Nyoman, I. B. (2011). Tradisi Ritual Materuna Nyoman Di Desa Adat Tenganan Pegeringsingan Kecamatan Manggis Kabupaten Karangasem. Bali: STKIP Amplapura.

Parniti, M. (1993). Tat Twam Asi, Cinta Kasih Universal “. Bali: Yayasan Dharma Nusantara dan FCHI.

Pegringsingan, D. A. (1841). Karangasem; Bali Patent No. -. 
Pujaastawa, I. (2001). "Tri Hita Karana”, Nilai-Nilai Lokal dalam Konteks Global. Brahma Carya Unikahidha Universitas Brawijaya Edisi II 2001/2002. Surabaya: Paramita.

Pujaastawa, I. (2002). Filosofis Kebudayaan Bali dari Perspektif Antropologi. surabaya: Paramita.

Suwardani, N. P. (2015). Pewarisan nilai-nilai kearifan lokal untuk memproteksi masyarakat Bali dari dampak negatif globalisasi. Jurnal Kajian Bali, 5(2), 247264.

Yasa, I. W. (2015). Catatan Desa Adat Tenganan Pegeringsingan. Karangasem. 